\title{
GAMBARAN STATUS HIDRASI PEKERJA DI LINGKUNGAN IKLIM PANAS: REVIEW LITERATURE
}

\author{
Rofi'atunnisa' \\ Universitas Lampung \\ Email: roftsa14@gmail.com
}

\begin{abstract}
The hot climate in the work environment can cause health hazards and disturbances to the workers, the working temperature environment exceeds the threshold value (TLV). This causes an increase in body fluids which helps balance the body which can cause workers to experience dehydration. Hydration status describes a condition that describes the condition of fluid balance in the body. When body fluids are in a state of deficiency or the status of the body is not normal, it can cause dehydration. In this case, many workers do not realize that they are not receiving fluids. The purpose of this paper's presentation was to see an overview of the hydration status of workers in a hot climate work environment. This paper uses an analytical method in the form of a literature review because it will analyze articles sourced from Google Scholar and Pubmed by entering keywords by the titles used in the period 2015-2020, the data obtained is then analyzed, arranged systematically, compared in terms of title, approach, objectives, results, and discussed. From this paper it was found that climate affects the hydration status of workers with the majority of workers found to be dehydrated.
\end{abstract}

Keywords: hydration status, dehydration, hot climate, workers

\begin{abstract}
Abstrak: Iklim panas di lingkungan kerja dapat berpotensi menimbulkan bahaya dan gangguan kesehatan terhadap pekerja apabila suhu lingkungan kerja melebihi nilai ambang batas (NAB). Hal ini menyebabkan peningkatan pengeluaran cairan tubuh sehingga mengganggu keseimbangan cairan tubuh yang dapat menyebabkan pekerja mengalami dehidrasi. Status hidrasi merupakan keadaan yang menggambarkan kondisi keseimbangan cairan dalam tubuh. Ketika cairan tubuh dalam keadaan kurang atau status hidrasi tubuh berada dalam keadaan tidak normal maka dapat menyebabkan dehidrasi. Dalam hal ini banyak pekerja yang sering tidak menyadari bahwa mereka kekurangan cairan. Tujuan dari pemaparan tulisan ini adalah untuk mengetahui gambaran status hidrasi pekerja pada lingkungan kerja dengan iklim panas. Pada tulisan ini menggunakan metode analisis berupa literatur review karena akan dianalisa artikel yang bersumber dari google scholar dan pubmed dengan memasukkan kata kunci yang sesuai dengan judul yang digunakan dalam kurun waktu antara tahun 2015 - 2020, Data yang diperoleh kemudian ditelaah, disusun secara sistematis, dibandingkan dari segi judul, pendekatan, tujuan, hasil, dan dibahas. Dari tulisan ini didapatkan hasil bahwa iklim panas mempengaruhi status hidrasi pada pekerja dengan mayoritas pekerja didapati mengalami dehidrasi.
\end{abstract}

Kata kunci: status hidrasi, dehidrasi, iklim panas, pekerja

\section{PENDAHULUAN}

telah $\begin{gathered}\text { Peningkatan suhu di seluruh dunia } \\ \text { mengakibatkan }\end{gathered}$ gelombang panas (panas ekstrim) yang dapat meningkatkan risiko morbiditas dan mortalitas. Suhu tinggi dapat menyebabkan peningkatan suhu tubuh, dehidrasi, dan hiperosmolalitas darah (Johnson et al., 2019). Banyak sekali masalah kesehatan kerja bagi pekerja yang perlu diperhatikan salah satunya kebutuhan gizi yaitu dari aspek kecukupan cairan yang dapat mempengaruhi kapasitas kerja (Ratih \& Dieny, 2017).

Iklim kerja diartikan sebagai perpaduan antara kelembaban, suhu, panas radiasi, dan gerakan udara dengan tingkat pengeluaran panas dari tubuh pekerja akibat dari aktivitas kerja. Iklim kerja dapat berpengaruh terhadap kejadian dehidrasi pada pekerja (Kemenaker RI, 2018).

Status hidrasi merupakan gambaran dari kondisi keseimbangan cairan tubuh. Apabila status hidrasi tubuh berada dalam keadaan tidak adekuat sehubungan dengan muntah, diare, pengaruh lingkungan bertekanan panas, berkeringat berlebihan akibat aktivitas berat, dan lain sebagainya. Dehidrasi berdampak buruk bagi tubuh manusia. Dehidrasi sedang atau dimana tubuh kehilangan $2 \%$ cairan dari berat badan akan mengganggu mood serta performa kognisi manusia (Nilamsari et al., 2018).

Dehidrasi merupakan keadaan tubuh yang mengalami kekurangan cairan 
dikarenakan jumlah cairan yang keluar dari tubuh lebih besar dari pada jumlah cairan yang masuk kedalam tubuh (N. A. Sari \& Nindya, 2017). Dehidrasi dapat disebabkan karena pendarahan dan kehilangan cairan. Apabila kebutuhan cairan tubuh meningkat, seperti suhu lingkungan yang tinggi, demam, dan aktivitas ekstrim hal ini dapat menyebabkan dehidrasi (Direktorat Kesehatan Kerja Kemenkes RI, 2014). Faktor risiko dehidrasi secara umum yaitu usia dewasa tua atau usia lanjut dan jenis kelamin laki-laki, suhu lingkungan yang tinggi, pengetahuan terhadap dehidrasi, asupan cairan yang kurang, suhu tubuh, aktivitas fisik tinggi, dan ketinggian suatu tempat (Leksana, 2015). Selain itu dehidrasi dapat dipengaruhi oleh faktor tingkat aktivitas fisik, kurangnya pengetahuan, kemudahan akses air minum yang aman dan bermutu (Fitriah et al., 2019).

Ginjal memiliki peran unik yaitu dengan melindungi tubuh dari panas dan dehidrasi (Johnson et al., 2019). Ginjal memiliki fungsi dalam menjaga volume darah yaitu untuk mendukung tekanan darah serta osmolalitas ekstraseluler dan intraseluler sehingga memungkinkan terjadinya metabolisme yang normal. Sayangnya, kerja metabolisme yang tinggi membuat ginjal sangat rentan cedera akibat perubahan iklim (Fischer \& Knutti, 2015).

\section{METODE PENELITIAN}

Metode yang digunakan dalam tulisan ini adalah literature review yang merupakan sebuah metode yang sistematis dengan tujuan menyajikan teori-teori yang relevan dengan permasalahan yang sedang diteliti. Penulis melakukan penelusuran artikel yang telah di publikasikan dalam bahasa Inggris bersumber dari Pubmed dan dalam bahasa Indonesia dari Google Cendikia. Adapun kriteria Inklusi dalam pemilihan artikel yaitu, a) Artikel diterbitkan dalam rentang waktu tahun 2015-2020, b) Artikel menggunakan rancangan kuantitatif. Kriteria eksklusinya yaitu, a) Tidak terlihat korelasi pada hasil yang didapat, b) Tidak terdapat kesesuaian antara isi artikel dengan permasalahan yang akan diteliti.

Penelusuran sumber dilakukan dengan memasukkan kata kunci yang sesuai dengan judul yang digunakan, untuk artikel dalam bahasa Inggris kata kunci
Pekerja yang bekerja dalam kondisi suhu lingkungan yang panas terutama jika dikombinasikan dengan kelembaban tinggi dapat menyebabkan hilangnya cairan dalam keringat, kegagalan untuk mengganti kehilangan cairan ini secara memadai dan tepat dapat menyebabkan dehidrasi progresif selama pekerja bekerja dalam waktu yang lama di lingkungan kerja yang panas dan dapat menyebabkan gejala seperti sakit kepala, kelesuan dan meningkatkan risiko cedera (Bates et al., 2010).

Pengeluaran cairan sebagian besar melalui urine atau saluran pencernaan, pengeluaran cairan dapat juga melalui kulit serta paru-paru, para pekerja sering tidak menyadari kalau mereka kekurangan cairan. Cairan yang hilang dan tidak diganti menyebabkan volume plasma menurun dan terjadi penurunan kemampuan fisik dan kognitif pekerja (Andayani \& Khairunissa, 2013). Hasil beberapa penelitian menunjukkan lingkungan kerja dengan iklim panas mempengaruhi status hidrasi pekerja. Tujuan dari literature review ini adalah untuk mengulas berbagai literatur terkait pengaruh lingkungan kerja dengan iklim panas terhadap status hidrasi pekerja agar dapat dilakukan upaya meminimalkan akibat dari dehidrasi pada pekerja.

yang digunakan adalah workers-hydration status-hot climate dan untuk artikel dalam bahasa Indonesia kata kunci yang digunakan adalah status hidrasi-pekerjaiklim panas. Hasil pencarian ditemukan pada Pubmed sebanyak 247.278 artikel dan Google Cendikia sebanyak 1.140 artikel. Artikel selanjutnya diseleksi berdasarkan kriteria inklusi yaitu artikel yang dipublikasikan dalam rentang waktu 20152020 didapatkan hasil pada Pubmed ditemukan 90.433 artikel dan Google Cendikia ditemukan 721 artikel. Selanjutnya dilakukan pemilihan artikel berdasarkan kesesuaian judul dengan tujuan artikel dan artikel yang memiliki kesamaan dilakukan eliminasi. Hasil akhir seleksi didapatkan 3 artikel bahasa Inggris dan 3 artikel bahasa Indonesia sehingga terdapat 6 artikel yang akan dianalisis. Data yang diperoleh kemudian ditelaah, disusun secara sistematis, dibandingkan dari segi judul, pendekatan, tujuan, hasil, dan dibahas. 


\section{HASIL PENELITIAN}

Hasil literature review didapatkan bahwa pekerja yang bekerja pada iklim yang panas dapat menyebabkan hilangnya cairan dan ketidakseimbangan cairan tubuh. Hal ini dapat menyebabkan dehidrasi pada pekerja. Berikut ini disajikan jurnal yang terkait antara lain sebagai berikut:

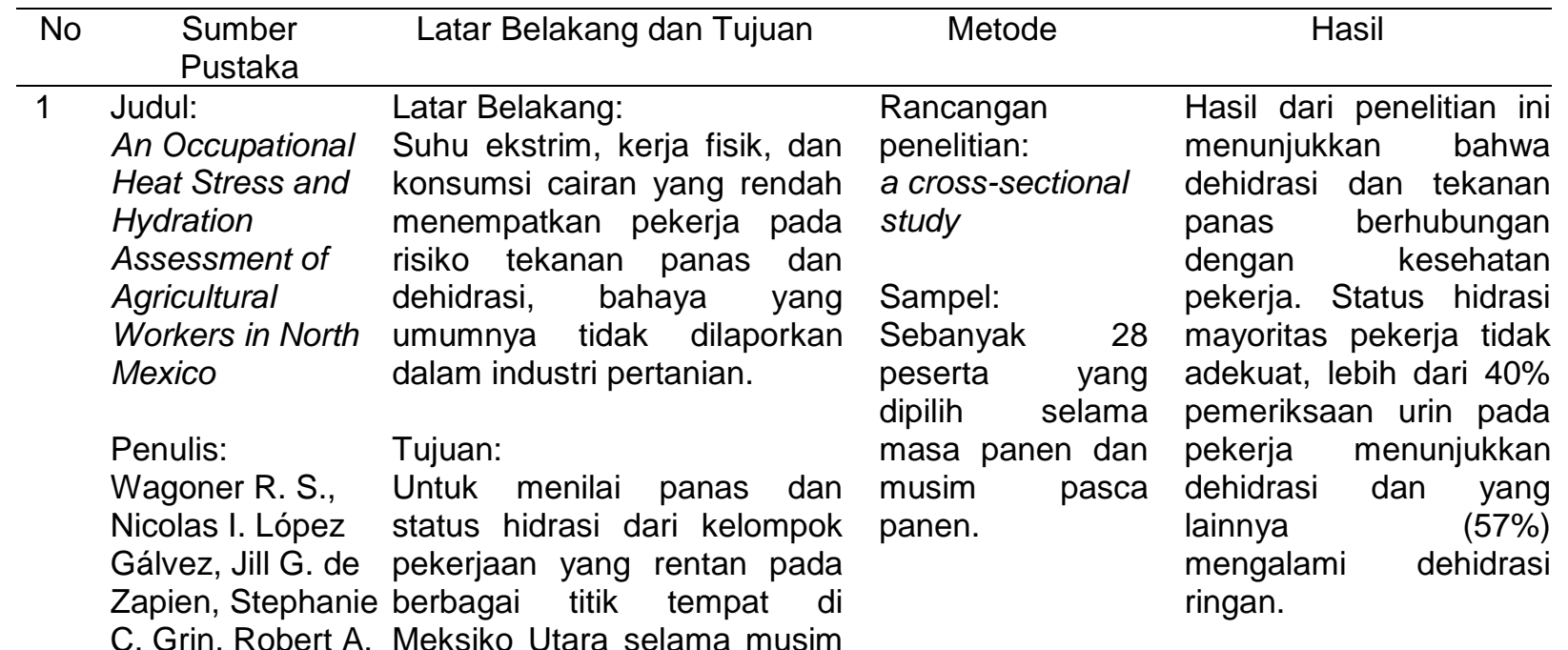

Canales and tanam

Paloma I. Beamer

Tahun: 2020

\begin{tabular}{ll}
\hline Judul: & Latar belakang: \\
Hydration Status & Dehidrasi yang terkait dengan \\
and Kidney & stres panas meningkatkan \\
Health of Factory & risiko cedera atau penyakit di \\
Workers & tempat kerja, menurunkan \\
Exposed to Heat & produktivitas, dan mungkin \\
Stress: A Pilot & berkontribusi pada epidemi \\
Feasibility Study & penyakit ginjal kronis yang \\
& diidentifikasi pada pekerja \\
Penulis: & outdoor di iklim panas. \\
Nerbass F. B., & Penelitian yang dilakukan \\
Louise Moist, & pada pekerja indoor tentang \\
William F. Clark, & efek stress panas akibat \\
Marcos A. Vieira, paparan panas yang terjadi \\
Roberto Pecoits- & terus menerus masih terbatas. \\
Filho & Tujuan: \\
& Bertujuan untuk mengukur \\
Tahun: 2020 & status hidrasi dan fungsi ginjal \\
& pada pekerja pabrik \\
& pengecoran di Brasil Selatan \\
& yang terpapar stress panas \\
& dan tidak terpapar stres \\
& panas.
\end{tabular}

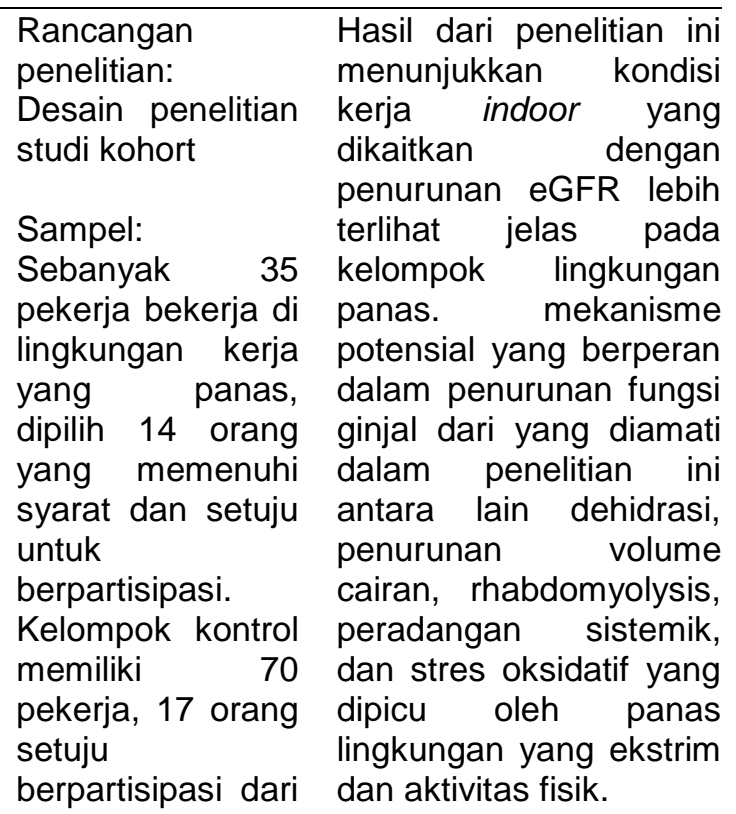

20 orang yang dipilih. Dua orang menolak karena alasan tertentu.

\begin{tabular}{lll}
\hline 3 & Judul: & Latar belakang: \\
Effects of & Banyak pekerja luar ruangan \\
hydration & tidak punya pilihan selain \\
practices on the & bekerja di tempat yang panas \\
severity of & dan terpapar matahari.
\end{tabular}

$\begin{array}{llr}\text { Rancangan } & \text { Persentase responden } \\ \text { penelitian: } & \text { yang mengalami HRI } \\ \text { A cross-sectional } & \text { sedang hingga berat } \\ \text { study } & \text { adalah } & 44,1 \% \\ & \text { Kemungkinan } & \text { pekerja }\end{array}$




\begin{tabular}{|c|c|c|c|c|}
\hline & $\begin{array}{l}\text { heatrelated } \\
\text { illness among } \\
\text { municipal } \\
\text { workers during a } \\
\text { heat wave } \\
\text { phenomenon } \\
\text { Penulis: } \\
\text { Mansor Z, MPH, } \\
\text { Rosnah Ismail, } \\
\text { DrPH, Noor } \\
\text { Hassim Ismail, } \\
\text { MSc, Jamal } \\
\text { Hisham Hashim, } \\
\text { PhD } \\
\text { Tahun: } 2019\end{array}$ & $\begin{array}{l}\text { Temperatur tempat kerja yang } \\
\text { tinggi dan } \text { tingkat } \\
\text { metabolisme yang tinggi } \\
\text { dapat membuat pekerja lebih } \\
\text { rentan mengalami penyakit } \\
\text { terkait panas (Heat Related } \\
\text { illness). } \\
\text { Tujuan: } \\
\text { Penelitian ini bertujuan untuk } \\
\text { mengevaluasi efek dari } \\
\text { praktik hidras (keteraturan } \\
\text { dan jenis cairan yang } \\
\text { dikonsumsi) dengan tingkat } \\
\text { keparahan HRI (heat related } \\
\text { illness) selama episode } \\
\text { gelombang panas di antara } \\
\text { pekerja kota di Negeri } \\
\text { Sembilan. }\end{array}$ & 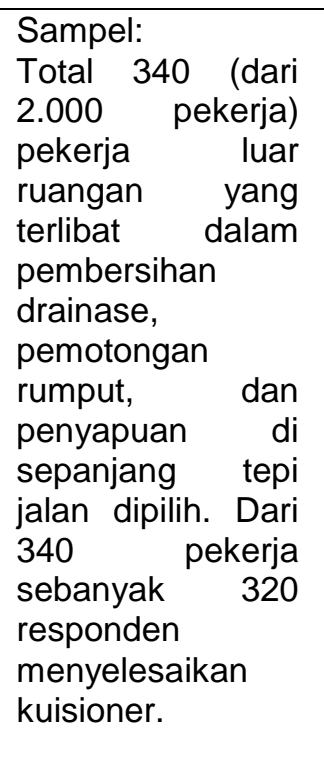 & 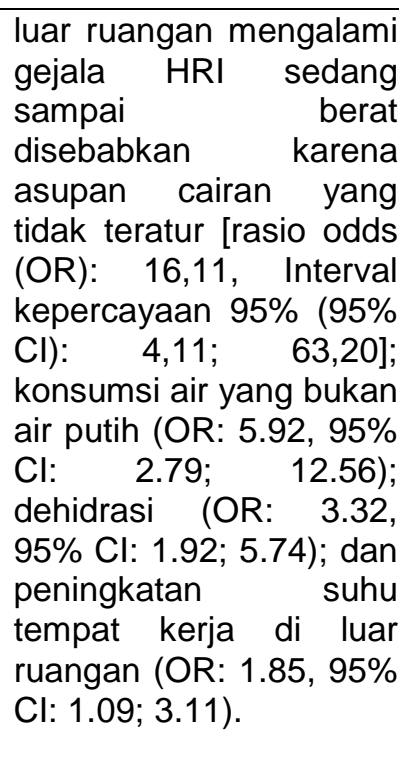 \\
\hline 4 & $\begin{array}{l}\text { Judul: } \\
\text { Gambaran Iklim } \\
\text { Kerja dan Tingkat } \\
\text { Dehidrasi Pekerja } \\
\text { Shift Pagi di } \\
\text { Bagian Inhection } \\
\text { Moulding } 1 \text { PT.X } \\
\text { Sidoarjo } \\
\text { Penulis: } \\
\text { Puspita A. D., } \\
\text { Noeroel Widajati } \\
\text { Tahun: } 2017\end{array}$ & 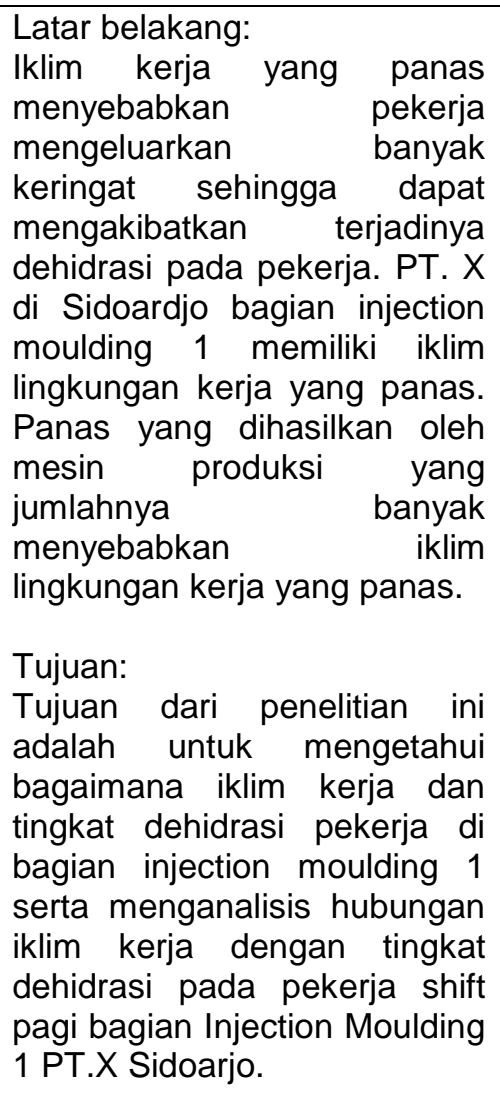 & $\begin{array}{l}\text { Rancangan } \\
\text { penelitian: } \\
\text { Merupakan } \\
\text { penelitian } \\
\text { observasional } \\
\text { dengan } \\
\text { pendekatan } \\
\text { cross-sectional. } \\
\text { Sampel: } \\
\text { Jumlah sampel } \\
\text { yang diteliti dalam } \\
\text { penelitian ini } \\
\text { sebanyak } \quad 31 \\
\text { orang yang } \\
\text { memenuhi kriteria } \\
\text { inklusi }\end{array}$ & $\begin{array}{lrr}\text { Dari } & \text { penelitian } & \text { ini } \\
\text { didapatkan hasil yaitu } & \text { has } \\
\text { adanya } & \text { hubungan } \\
\text { antara iklim } \text { kerja } \\
\text { dengan } \\
\text { dehidrasi. Penelitian ini } \\
\text { juga menunjukkan } \\
\text { bahwa suhu lingkungan } \\
\text { di PT. X melebihi nilai } \\
\text { ambang batas (NAB). }\end{array}$ \\
\hline 5 & $\begin{array}{l}\text { Judul: } \\
\text { Iklim Kerja Panas } \\
\text { dan Konsumsi Air } \\
\text { Minum Saat Kerja } \\
\text { Terhadap } \\
\text { Dehidrasi } \\
\text { Penulis: Sari M. } \\
\text { Puspita } \\
\text { Tahun: } 2017\end{array}$ & $\begin{array}{l}\text { Latar belakang: } \\
\text { Lingkungan kerja yang panas } \\
\text { dan jika pekerja terpapar terus } \\
\text { menerus dapat menyebabkan } \\
\text { gangguan kesehatan, salah } \\
\text { satunya adalah dehidrasi. } \\
\text { Bagian weaving merupakan } \\
\text { salah satu proses produksi } \\
\text { yang memiliki lingkungan kerja } \\
\text { panas melebihi NAB. } \\
\text { Tujuan: } \\
\text { Tujuan dari dilakukannya }\end{array}$ & $\begin{array}{l}\text { Rancangan } \\
\text { penelitian: } \\
\text { Merupakan } \\
\text { penelitian survey } \\
\text { analitik dengan } \\
\text { pendekatan cross } \\
\text { sectional. } \\
\\
\text { Sampel: } \\
\text { Sampel dari } \\
\text { penelitian ini } \\
\text { sebanyak } 53 \\
\text { pekerja dari total }\end{array}$ & 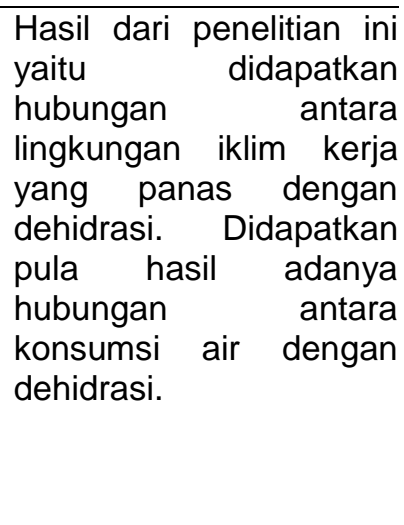 \\
\hline
\end{tabular}




\begin{tabular}{|c|c|c|c|c|}
\hline & & $\begin{array}{l}\text { penelitian ini adalah untuk } \\
\text { mengetahui hubungan iklim } \\
\text { kerja panas dan konsumsi air } \\
\text { minum dengan dehidrasi pada } \\
\text { pekerja PT. Candi Mekar } \\
\text { Pemalang bagian weaving. }\end{array}$ & 111 pekerja & \\
\hline 6 & $\begin{array}{l}\text { Judul: } \\
\text { Paparan Iklim } \\
\text { Kerja Panas } \\
\text { Terhadap Status } \\
\text { Hidrasi Pekerja } \\
\text { Unit Produksi di } \\
\text { PT. Argo Pantes } \\
\text { Tbk Tangerang } \\
\text { Penulis: Rasyid. } \\
\text { R } \\
\text { Tahun: } 2017\end{array}$ & 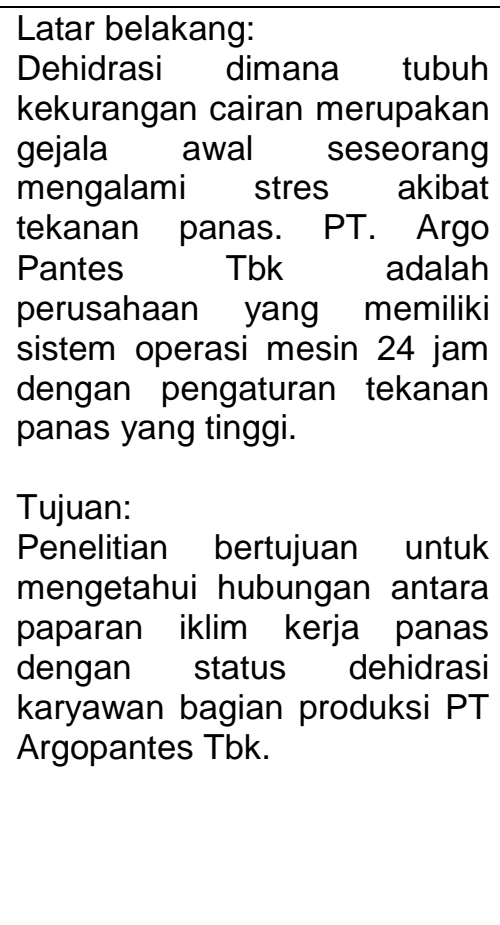 & $\begin{array}{l}\text { Rancangan } \\
\text { penelitian: } \\
\text { Metode penelitian } \\
\text { yang digunakan } \\
\text { adalah metode } \\
\text { kuantitatif analitik } \\
\text { dengan desain } \\
\text { cross-sectional. } \\
\text { Sampel: } \\
\text { Sampel penelitian } \\
\text { ini merupakan } \\
\text { pekerja di unit } \\
\text { produksi PT. Argo } \\
\text { Pantes Tbk } \\
\text { berjumlah } \quad 73 \\
\text { pekerja. }\end{array}$ & 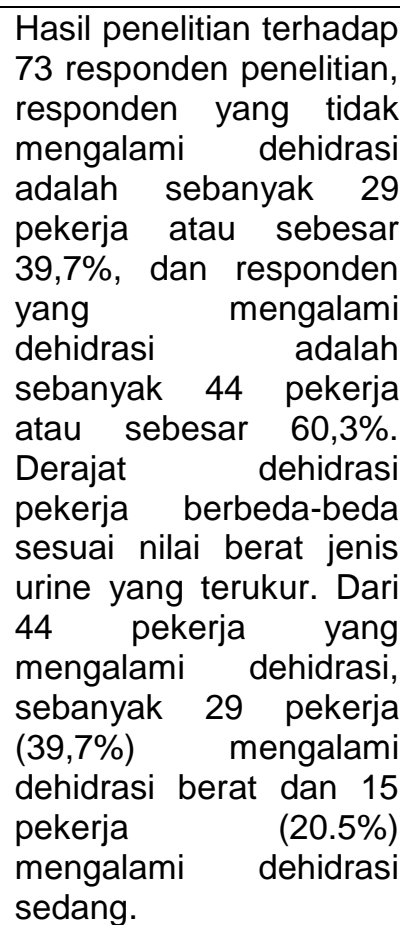 \\
\hline
\end{tabular}

\section{PEMBAHASAN}

Status hidrasi merupakan penentu penting dari kemampuan tubuh untuk mentolerir stres panas. Kandungan air dalam tubuh menentukan kapasitas penyimpanan panas. Untuk pekerja yang melakukan pekerjaan manual dalam kondisi iklim panas tingkat hidrasi yang baik sangat penting untuk meminimalkan risiko penyakit akibat stres panas dan menghindari kelelahan yang berlebihan (Bates et al., 2010).

Pekerja yang tergolong usia muda merupakan tenaga kerja yang berusia dibawah 40 tahun, Pekerja yang berusia muda dapat mentolerir pengaruh suhu tinggi, karena pada usia muda lebih sedikit menyerap panas dan tubuh lebih cepat mengalami aklimatisasi, tetapi tidak dianjurkan terlalu lama berada ditempat kerja yang bersuhu tinggi karena akan berakibat buruk terhadap kesehatan pekerja. Pekerja yang berusia lebih dari 40 tahun memiliki kelenjar keringat yang menunjukkan respon lebih lambat terhadap beban panas metabolik dan lingkungan sehingga pekerja yang berusia diatas 40 tahun sebaiknya tidak ditempatkan pada tempat kerja yang panas (Puspita et al., 2017).

Pekerja dengan masa kerja panjang tentunya sudah terbiasa berada di lingkungan kerja yang panas. semakin lama masa kerja seseorang kemungkinan besar orang tersebut telah mengalami aklimatisasi terhadap iklim kerja (M. P. Sari, 2017). Proses aklimatisasi yang sudah baik tidak menjamin pekerja tersebut terhindar dari risiko gangguan kesehatan akibat bekerja di lingkungan yang panas misalnya dehidrasi. Tingkat dehidrasi seseorang tidak hanya ditentukan dari lamanya orang tersebut bekerja atau berada di tempat yang panas. Faktor penyebab pekerja mengalami dehidrasi bermacam-macam, contohnya kurangnya konsumsi cairan atau akibat penyakit tertentu,dll (Puspita et al., 2017).

Pekerjaan yang di lakukan pada lingkungan yang panas tidak boleh dilakukan secara terus-menerus tetapi harus diselingi dengan istirahat yang cukup, 
Tujuan adalah untuk memberi kesempatan tubuh melakukan pemulihan (Puspita et al., 2017). Bagi manusia dehidrasi memiliki dampak yang buruk, kekurangan cairan dalam tubuh yang merupakan tanda dehidrasi adalah gejala awal seseorang mengalami stres akibat tekanan panas (Rasyid, 2017).

Kebiasaan minum pekerja yang minum pada saat haus saja merupakan kebiasaan yang tidak baik, karena mekanisme haus tidak mampu untuk membuat pekerja minum sesuai dengan jumlah cairan yang hilang melalui keringat, sehingga hal ini cenderung menyebabkan defisit cairan. Tenaga kerja yang bekerja ditempat panas harus minum sesering mungkin setidaknya 200 cc sampai 300 cc tiap 30 menit. Tujuannya antara lain agar cairan tubuh tetap dalam keadaan seimbang. Namun tidak menjadi patokan seseorang harus minum sebanyak $200 \mathrm{cc}$ sampai $300 \mathrm{cc}$ air tiap 30 menit, melainkan yang terpenting adalah anjuran pada pekerja yang bekerja di tempat yang panas untuk minum air sesering mungkin (Puspita et al., 2017).

Pada beban kerja yang ringan dengan durasi kerja $75 \%$ sampai dengan $100 \%$ suhu panas lingkungan yang dapat ditolerir sebesar $30^{\circ} \mathrm{C}$ dan untuk beban kerja sedang adalah $28^{\circ} \mathrm{C}$. Sedangkan untuk beban kerja berat dengan durasi kerja $75 \%$ sampai dengan $100 \%$ tidak dapat ditolerir sama sekali sehingga tidak memiliki nilai ambang batas ISBB (Kemenakertrans RI, 2011).

Tahap awal sebelum tubuh benar benar kekurangan cairan atau dehidrasi disebut pre dehidrasi. Pada tahap dehidrasi ringan tubuh sudah mengalami tanda-tanda dehidrasi seperti haus, lelah, lemah, sedikit gelisah, dan hilang selera makan, pada tahap ini tubuh kekurangan cairan sebesar $1 \%$ sampai $2 \%$. Pada tahap dehidrasi sedang tubuh sudah mengalami tandatanda dehidrasi seperti kulit kering, volume urin berkurang, mulut dan tenggorokan kering dimana pada tahap ini tubuh kekurangan cairan sebesar 3\% sampai $4 \%$. Pada tahap tubuh mengalami kekurangan cairan sebanyak $5 \%$ sampai $6 \%$ tubuh mengalami tanda-tanda dehidrasi seperti sakit kepala, sulit berkonsentrasi, kegagalan pengaturan suhu tubuh serta peningkatan frekuensi nafas. Saat tubuh kehilangan cairan sebesar $>6 \%$ dapat meningkatkan risiko gangguan kesehatan, seperti dapat mengakibatkan otot kaku dan collapse, ketika tubuh kehilangan cairan sebesar $7 \%$ sampai $10 \%$ dapat menyebabkan penurunkan volume darah. serta saat tubuh kehilangan cairan sebesar $11 \%$ dapat berakibat kegagalan fungsi ginjal (Gustam, 2012).

Dehidrasi biasanya terjadi pada pekerja sektor pertanian dan pekerjaan yang membutuhkan aktifitas fisik (Wagoner et al., 2020). Mekanisme potensial yang dapat menyebabkan penurunan fungsi ginjal antara lain dehidrasi, penurunan volume cairan tubuh, rhabdomyolysis, peradangan sistemik, dan stres oksidatif yang dipicu oleh panas lingkungan dan aktivitas fisik yang ekstrim (Nerbass et al., 2019).

Minum air yang bukan air mineral seperti minuman yang berkafein, manis, atau minuman yang berkarbonasi menyebabkan resiko mengalami heat related illness lebih tinggi. Minuman berkafein terbukti meningkatkan suhu inti tubuh, sebanyak 0,3 ${ }^{\circ} \mathrm{C}$ untuk setiap 2,9 $\mathrm{mg} / \mathrm{kg}$ kafein. Minuman berkafein juga memiliki efek diuretik, yang akan meningkatkan terjadinya kehilangan cairan dan elektrolit. Laju rehidrasi tubuh dan heat loss mechanism dapat dipengaruhi oleh minuman manis, terutama bila kandungan karbohidratnya melebihi osmolaritas plasma normal (290 mosmol / kg) yang mana menyebabkan penyerapan cairan ke dalam plasma lebih lambat. Minuman berkarbonasi juga dapat meningkatkan tingkat metabolisme, yang dapat meningkatkan suhu inti tubuh (Mansor et al., 2019).

Orang yang bertubuh gemuk kurang baik bekerja di lingkungan kerja yang panas, hal ini dikarenakan lemak dalam tubuh merupakan isolasi panas yang baik bagi tubuh karena tubuh mengabsorbsi panas dari lingkungan tetapi sulit untuk melepaskannya (Metta, 2012). Oleh karena itu, disarankan orang yang mempunyai status gizi yang baik untuk bekerja dalam lingkungan kerja yang panas. Hal ini juga dikarenakan proporsi ukuran tubuh berbanding lurus dengan kebutuhan cairan, selain itu komposisi yang ada dalam tubuh pun ikut mempengaruhi jumlah total cairan dalam tubuh (M. P. Sari, 2017). 


\section{KESIMPULAN DAN SARAN}

Penelitian ini menunjukkan terdapat hubungan antara iklim kerja panas dengan status hidrasi pekerja. Dimana mayoritas pekerja yang bekerja pada lingkungan dengan iklim kerja yang panas mengalami dehidrasi. Perlunya menjaga asupan cairan sesuai kebutuhan cairan tubuh untuk mencegah terjadinya dehidrasi. Hal ini dapat dilakukan dengan cara meletakkan

\section{DAFTAR PUSTAKA}

Andayani, \& Khairunissa. (2013). Hubungan Konsumsi Cairan Dengan Status Hidrasi Pada Pekerja Industri LakiLaki [Skripsi]. Universitas Diponegoro.

Bates, G. P., Miller, V. S., \& Joubert, D. M. (2010). Hydration status of expatriate manual workers during summer in the Middle East. Annals of Occupational Hygiene, 54(2), 137-143.

https://doi.org/10.1093/annhyg/mep0 76

Direktorat Kesehatan Kerja Kemenkes RI. (2014). Pedoman kebutuhan cairan bagi pekerja agar tetap sehat dan produktif (Edisi 1).

Fischer, \& Knutti. (2015). Anthropogenic contributionto global occurrence of heavy precipitation and high temperature extremes. Nat Clim Chang, 5(6), 560-564.

Fitriah, N., Setyawan S, H., Adi, M. S., \& Udiyono, A. (2019). Faktor Risiko Kejadian Dehidrasi pada Petani Garam di Kecamatan Kaliori, Kabupaten Rembang. Jurnal Epidemiologi Kesehatan Indonesia, 2(2), 49-54. https://doi.org/10.7454/epidkes.v2i2. 1843

Gustam. (2012). Faktor Risiko Dehidrasi pada Remaja dan Dewasa [Skripsi]. Departemen Gizi Masyarakat Fakultas Ekologi.

Johnson, R. J., Sánchez-Lozada, L. G., Newman, L. S., Lanaspa, M. A., Diaz, H. F., Lemery, J., RodriguezIturbe, B., Tolan, D. R., ButlerDawson, J., Sato, Y., Garcia, G., Hernando, A. A., \& Roncal-Jimenez, beberapa galon air mineral di tempat yang mudah dijangkau oleh pekerja. Selain itu, diperlukan juga edukasi terkait kebutuhan cairan pekerja pada lingkungan kerja yang panas, edukasi mengenai tanda-tanda dehidrasi, akibat dehidrasi, dan cara pencegahan dehidrasi kepada para pekerja. Selain itu pada tempat kerja indoor diberikan penambahan ventilasi berupa pembuatan lubang pada tembok untuk mengurangi suhu panas.

C. A. (2019). Climate Change and the Kidney. Annals of Nutrition and Metabolism, 74(Suppl3), 38-44. https://doi.org/10.1159/000500344

Kemenaker RI. (2018). Peraturan menteri Ketenagakerjaan Republik Indonesia Nomor 5 Tahun 2018 Tentang Keselamatan dan Kesehatan Kerja Lingkungan Kerja. Kementrian Tenaga kerja.

Kemenakertrans RI. (2011). Peraturan Menteri Tenaga Kerja dan Transmigrasi Nomor 13 Tahun 2011 tentang Nilai Ambang Batas Faktor Fisika dan Faktor Kimia di Tempat Kerja. Kementerian Tenaga Kerja \& Transmigrasi.

Leksana. (2015). Strategi Terapi Cairan pada Dehidrasi. 42(1), 70-73.

Mansor, Z., Ismail, R., Ismail, N. H., \& Hashim, J. H. (2019). Effects of hydration practices on the severity of heat-related illness among municipal workers during a heat wave phenomenon. Medical Journal of Malaysia, 74(4), 275-280.

Metta. (2012). Sehat dengan Air Putih. Stomata.

Nerbass, F. B., Moist, L., Clark, W. F., Vieira, M. A., \& Pecoits-Filho, R. (2019). Hydration Status and Kidney Health of Factory Workers Exposed to Heat Stress: A Pilot Feasibility Study. Annals of Nutrition and Metabolism, 74(Suppl3), 30-37. https://doi.org/10.1159/000500373

Nilamsari, N., Damayanti, R., \& Nawawinetu, E. D. (2018). Hubungan Masa Kerja Dan Usia Dengan Tingkat Hidrasi Pekerja Perajin Manik-Manik Di Kabupaten 
Jombang. Jurnal Kesehatan Terpadu (Integrated Health Journal), 9(2), $1-9$. https://doi.org/10.32695/jkt.v2i9.14

Puspita, A. D., Widajati, N., Studi, P., Masyarakat, K., Masyarakat, F. K., \& Airlangga, U. (2017). Gambaran Iklim Kerja dan Tingkat Dehidrasi Pekerja Shift Pagi di Bagian Injection Moulding 1 PT.X Sidoarjo. 1(1), 13-21.

Rasyid, R. (2017). Paparan Iklim Kerja Panas Terhadap Status Hidrasi Pekerja Unit Produksi di PT. Argo Pantes Tbk Tangerang. Jurnal Teknik Mesin ITI, 1(1), 18. https://doi.org/10.31543/jtm.v1i1.11

Ratih, A., \& Dieny, F. F. (2017). Hubungan Konsumsi Cairan Dengan Status Hidrasi Pekerja di Suhu Lingkungan Dingin. Journal of Nutrition College,
6(1), 76-83.

Sari, M. P. (2017). Iklim Kerja Panas dan Konsumsi Air Minum Saat Kerja Terhadap Dehidrasi. HIGEIA (Journal of Public Health Research and Development), 1(2), 108-118.

Sari, N. A., \& Nindya, T. S. (2017). Hubungan Asupan Cairan , Status Gizi Dengan Status Hidrasi Pada Pekerja Di Bengkel Divisi General. Media Gizi Indonesia, 12, 2. nika.anitas@gmail.com

Wagoner, R. S., López-Gálvez, N. I., de Zapien, J. G., Griffin, S. C., Canales, R. A., \& Beamer, P. I. (2020). An occupational heat stress and hydration assessment of agricultural workers in north mexico. International Journal of Environmental Research and Public Health, 17(6). https://doi.org/10.3390/ijerph17062102. 